been a significant change in either or both of the photo-cells or in the light source the null reading will not be obtained, and the light to the balancing photo-cell will have to be readjusted to give a null reading before repeating the estimation. The estimation is reliable only when the null reading is obtained with the standard filter both before and after making the estimation with the blood solution.

As the standard filter and the blood solution do not necessarily transmit the same wave-lengths, it is essential, for this procedure to give accurate results, either that any change in current output from the photo-cell must be the same for all effective wavelengths or the range of wave-length employed must be so narrow that such a wave-length difference, if it occurs, is without effect.

Our justification for claiming that changes in light intensity and in the condition of the photo-cells need not cause error is this: With an absorptiometer of the opposed-cell type using barrier-layer selenium photo-cells and $\mathrm{NaOH}$-blood solutions, the reading on the instrument for a given solution is unaltered with wide differences of light intensity; further, the haemoglobin value of a solution determined immediately the photo-cells are illuminated is unchanged when redetermined after the apparatus has been in use for some hours, when the condition of the cells has markedly altered (as shown by the galvanometer deflection produced by standard illumination).

\section{Some Observations}

In estimating haemoglobin by photo-electric means we have made a few other observations that may be of interest. Certain advantages of the alkaline haematin method have already been advanced by Clegg and King (1942). In some ways the procedure employed in the present work differs from that of other workers. It has been found that accurate measurements can be made with $\mathrm{NaOH}$-blood solutions without the necessity for cither heating the alkaline solutions or forming alkaline haematin indirectly by conversion from acid haematin. 0.02 or $0.04 \mathrm{ml}$. of human blood added to $5 \mathrm{ml}$. of decinormal $\mathrm{NaOH}$, estimated within five minutes, gives a value greater than $95 \%$ of the maximum. For very accurate work it is an advantage to let the solution stand overnight and to use only the supernatant liquid. There is always a slight deposit, but the supernatant liquid gives a constant maximum absorption for about five days. This rapid rate of denaturation is not necessarily true of all bloods. That of the ox, for example, requires some hours for a satisfactory equilibrium to be established.

A further advantage in the use of a strong alkali lies in the fact that while slight clotting in the pipette, which may be undetected by macroscopic examination, causes-a considerable error in the absorptiometric estimation of an aqueous oxyhaemoglobin solution, the clot is readily broken down in decinormal $\mathrm{NaOH}$ and the supernatant fluid gives a true reading.

The region of the spectrum best suited for accurate photoelectric estimation of alkaline haematin has been investigated, employing a wide range of colour filters. A spectroscopic examination of two alkaline blood solutions, representing extremes of concentration of haemoglobin, show marked differences in light absorption in three regions of the visible spectrum-viz., (1) in the band about $600 \mathrm{~m} \mu,(2)$ in the long-wave end about $750 \mathrm{~m} \mu$, and (3) in the short-wave end to about $495 \mathrm{~m} \mu$ for the weaker solution and to about $525 \mathrm{~m} \mu$ for the stronger. Decidedly the best results, as measured by change in photo-cell current with change in haemoglobin concentration, have been obtained in this last region using a Wratten 45A filter, which gives light transmission from $430 \mathrm{~m} \mu$ to $540 \mathrm{~m} \mu$, with maximum at $470 \mathrm{~m} \mu$ and a smaller transmission in the ultra-violet. This absorption region is not so specific for alkaline haematin as is the $600 \mathrm{~m} \mu$ band, but the degree of change of absorption with change in concentration of alkaline haematin, as indicated by the photocell, is so much greater here than in the $600 \mathrm{~m} \mu$ band, as delimited by available colour filters, that its use is justified. In estimating total blood pigment, the lack of specificity of the shorter-wave region could be significant only if one were dealing with abnormal blood containing an appreciable quantity of some pigment not convertible to alkaline haematin by decinormal $\mathrm{NaOH}$. Further, in the wave-length range transmitted by the Wratten $45 \mathrm{~A}$ colour filter the absorption by blood plasma is insignificant, as shown by the extent to which the absorption by decinormal $\mathrm{NaOH}$ is increased by the addition of plasma to it. In a series of experi- ments the addition of $0.02 \mathrm{ml}$. of plasma to $5 \mathrm{ml}$. of decinormal $\mathrm{NaOH}$ did not, in any instance, increase the absorption by more than the equivalent of $0.1 \mathrm{~g}$. $\mathrm{Hb}$ per $100 \mathrm{ml}$. of blood, and in some instances there was no increase. It is obvious that the plasma plays no significant part in the estimation.

The accuracy obtained in photo-electric estimation of alkaline solutions of blood is highly satisfactory. Replicates of $0.02 \mathrm{ml}$. from the same sample of blood with an oxygen capacity of about $20 \mathrm{ml}$. per $100 \mathrm{ml}$. of blood can be estimated with a standard deviation of 0.1 and with a standard error of 0.04 for twelve estimations. When $0.04 \mathrm{ml}$. of blood is used the error is less.

In the absence of an absolute standard of reference we have expressed our measurements in terms of oxygen capacity, and have found that the curve relating absorptiometer reading to relative concentrations of haemoglobin, as determined by exact dilution, coincides satisfactorily with that relating absorptiometer reading to oxygen capacities of the same relative magnitudes and determined by the van Slyke manometric method.

From the observations made it seems justifiable to claim that the reliability of the absorptiometric method of measurement here described is such that, provided the blood does not contain appreciable quantities of haemoglobin derivatives inconvertible to alkaline haematin by decinormal $\mathrm{NaOH}$, the only significant errors involved in estimating the total pigment lie in the sampling (Peterson, Strangeways, and Jordan, 1943) and in the lack of an absolute standard.

\section{Summary}

An answer is given to the criticism that changes in light intensity and in the electric properties of the photo-cell result in unavoidable errors in the absorptiometric estimation of haemoglobin. Certain facts relating to the accuracy of the estimation are discussed.

\section{REFERENCES}

Clegg, J. W., and King, E. J. (1942).

Peterson, J. M., Strangeways, D. H., and Jordan, R. C. (1943). J. Physiol., 102, $5 \mathrm{P}$.

\section{Medical Memoranda}

\section{Staphylococcal Pyopneumothorax in an Infant : Recovery}

The following case record may be thought interesting enough to merit publication.

\section{CASE History}

A female infant was born of a healthy mother on Dec. 14, 1942, at the West Middlesex County Hospital. The infant weighed $7 \mathrm{lb} .5 \mathrm{oz}$. at birth and progressed satisfactorily until Dec. $20 \mathrm{on}$ breast-feeds complemented with national dried milk. On that date she developed diarrhoea, with orange stools, and vomited once. She was transferred to the children's isolation ward, where she was found to be slightly dehydrated. She seemed to make a little progress on graduated feeds (glucose-saline, dilute lactic acid milk, and expressed breast milk) until Dec. 31 , when she suddenly became much worse, with watery orange stools and severe dehydration. An intravenous drip was necessary to correct the latter, and, owing to the poor oral intake of fluids, was continued until Jan. 6,1943. By that time she had developed thrombophlebitis of the internal saphenous vein, into which the drip was running. She had a slight temperature for two days, but this subsided when the drip was stopped. She also had two septic fingers and a septic toe. She improved sufficiently to go to the breast, for the mother's milk was coming in better by then On Jan. 13 she suddenly collapsed at the breast, and was found to be pale, cyanosed, and almost pulseless. Later, when examination was possible, her temperature was $103^{\circ} \mathrm{F}$., pulse 140 , and respirations 48 . The percussion note was impaired at the left base, where bronchial breathing and pleural rub were found on auscultation. A diagnosis of pneumonia was made, and the child was put in an oxygen tent and given a course of sulphadiazine $(8 \mathrm{~g}$. in six days)

During the next week the temperature subsided but did not reach normal, and the respiration rate increased. On Jan. 21 slight oedema of the legs was noticed. By the next morning the oedema was so gross that the legs looked like sausages, and the body wall was also dropsical. On examination of the chest the respiratory excursions aropsical. On examination of the chest the 60 , heart sounds muffled at the left base and accompanied by harsh crepitations. The apex beat could not be located. A radiograph (portable) revealed gross displacement of the mediastinum, which was bowed out almost into the right axilla. It was thought that this bowing might have kinked the inferior vena cava, thus causing the oedema of the legs. 
The child's appearance at this time was ghastly, with half-closed upturned eyes, greyish pallor, scarcely perceptible thoracic movements, a grossly distended abdomen, and swollen legs. The chest was needled at 9 p.m. on Jan. 22 and air rushed out under pressure. About $50 \mathrm{c.cm}$. was withdrawn. The oedematous legs were scarified and wrapped in sterile dressings. Next morning there was no oedema, nor did it subsequently reappear. Re-exploration of the chest resulted in a small quantity of pus but no air. On Jan. 24 another $50 \mathrm{c} . \mathrm{cm}$. of air and a little pus were aspirated. On the $25 \mathrm{th}$ another $50 \mathrm{c.cm}$. of air and a little pus were aspirated. On the $25 \mathrm{th}$
about $20 \mathrm{c.cm}$. of thick greenish-yellow pus was withdrawn. From the pus on each occasion Staph. aureus was cultured.

In view of the large quantity of pus obtained, closed intercostal drainage was decided upon, and at 12.30 p.m. on Jan. 25 a rubber catheter was inserted by means of a trocar without anaesthesia. A considerable quantity of pus gushed out under pressure. The apparent relief was immediate, the respiration rate falling from 100 to 45 in a few minutes. Continuous underwater drainage was maintained for three days, when the pus became too thick to pass through the catheter, so a wider tube was inserted. A radiograph taken on Jan. 28 showed the return of the heart to a more normal position. By the 31 st there was very little discharge, and closed drainage was replaced by a short tube draining into the dressings. Between Jan. 26 and Feb. $2,8 \mathrm{~g}$. of sulphathiazole were given and a suspension of sulphapyridine powder was instilled into the pleural cavity twice a day.

The infant was not yet out of the wood. Her respiration rate had again risen to 70-80; this was partly attributable to the gross abdominal distension, which resisted all forms of treatment, such as charcoal by mouth, pitressin by injection, and the passage of a flatus-tube. The diarrhoea had by this time quite subsided, and she was taking bottle feeds of breast milk well. On Feb. 5 the temperature once more shot up to $103^{\circ}$. The signs suggested a left-upperlobe pneumonia. There was scarcely any discharge from the sinus, and needling failed to reveal pus elsewhere. She was given yet another course of sulphadiazine $(8$ g.) and local irrigations with $1 / 2000$ propamidine b.d., but she continued to run an intermittent though subsiding temperature until Feb. 27. On Feb. 13 she was put to the breast, and later resolutely refused bottle feeds; within 24 hours she was for the first time entirely breast-fed. From that time she never looked back, and was discharged on March 8, weighing $7 \mathrm{lb}$. $12 \mathrm{oz}$. and gaining steadily. The sinus was by then completely healed.

In addition to the above therapeutic measures she received three transfusions of fresh citrated blood $(450 \mathrm{c.cm}$. in all) on Jan. 25 , Feb. 2, and Feb. 19. She also had a course of vitamin $B$ injections (1 mg. daily for three weeks).

Two radiographs were taken after discharge. The first, on March 12, showed that the left costophrenic angle was almost clear, but there were signs of bilateral bronchopneumonia. She was last seen on April 2, when she was a bonny child weighing 9 lb. $9 \frac{1}{2}$ oz. (a gain of nearly $2 \mathrm{lb}$. in $3 \frac{1}{2}$ weeks), entirely breast-fed and showing no signs of her stormy passage except the four transfusion scars, a minute scar at the site of the intercostal drain, and a scarcely perceptible radiographic shadow at the left costophrenic angle.

\section{COMMENT}

The pyopneumothorax in this case may be assumed to have been due to the rupture into the pleural cavity of a lung abscess, itself caused by a septic embolus. Staphylococcal lung abscesses have been reported following skin sepsis (the infant had septic fingers from the start), but a more likely source in this case was the thrombophlebitis caused by the perhaps unduly prolonged intravenous drip. The rupture of the abscess into the pleura may be assumed to have occurred on Jan. 21 , when oedema of the legs appeared and the signs of respiratory distress became acute.

Features of interest in this case are: (1) the remarkable degree of mediastinal displacement, the presumed cause of the oedema of the legs ; (2) the child's recovery from such a severe illness starting at the age of 1 month, when she was not yet through an attack of neonatal diarrhoea-itself having a mortality rate of $80 \%$; (3) the successful establishment of breast-feeding after the mother had been expressing her milk during the month the child was in the oxygen tent.

I wish to thank Dr. Cook, medical superintendent of West Middlesex County Hospital, for permission to publish this case, and Messrs. May and Baker for the supply of propamidine used in irrigations. I would also like to express my appreciation to the nursing staff concerned, and especially to Sister Jones and Staff Nurse Moloney, on whom the bulk of the nursing of this exacting case depended.

\section{Patria Gairdner, M.D., M.R.C.P.,}

Assistant M.O.H., Oxfordshire County Council.

T. C. Jaleski and E. T. Morrison (Amer. J. med. Sci., 1943, 206, 449), who report two cases in healthy adults, state that congenital heart block is rare, only 80 cases having been described up to 1942 . The first case, which had been studied for five years, was a healthy woman, aged 20, with no cardiac symptoms and no other apparent anomalies. The second case was a woman, aged 31 , who had been followed from birth and had had no cardiac symptoms except for some syncopal attacks. She had had two normal pregnancies without any serious cardiac disturbance.

\section{Reviews}

\section{ALMROTH WRIGHT'S COLLECTED PAPERS}

Studies on Immunization. First Series. Researches from the Inoculation F.R.S. (Pp. 421. 25s.) London: William Heinemann. 1943.

Some time ago (Aug. 8, 1942) we reviewed a volume containing papers written by Sir Almroth Wright during and shortly after the last war on The Pathology and Treatment of War Wounds. This was the first of a projected series of five republications in book form of the work of Wright and his collaborators.

Volume III is entitled, Studies on Immunization. First Series, and though a reprint with few changes of a book published in 1909 it actually consists of papers originally published between 1897 and 1908. There are very few living medical authors who could republish so imposing a body of work mainly carried out more than forty years ago, and fewer still, if any, who would venture to do so if they could. The earliest papers are among the most interesting, and almost unconnected with the main subject of the book: that by C. Birt and G. Lamb on the agglutinin content of the blood in what we now call undulant fever, and its variations in the course of the disease, contains much useful information. The rest, which treats of the therapeutic use of vaccines, can be looked upon in one or other of three ways.

It is certainly a convenient reassembly of historic papers, which will save the inquirer trouble in obtaining the originals: during the present scarcity of paper for more urgent scientific purposes this in itself does not seem a sufficient reason for printing such a book. The author's own view, expressed in a foreword written for this publication, is that practitioners not conversant with some of its principles are " not properly qualified to take charge of patients suffering from bacterial infections." In fact he seems to stand by his earlier pronouncements, and would presumably still advocate the treatment of tuberculosis by injections of tuberculin controlled by opsonic index estimations, as well as other forms of vaccine treatment the efficacy of which is not generally admitted. We venture to predict that few readers will accept this judgment. It would be surprising if ideas developed so early in the evolution of a young science remained fully acceptable at the present day, and, as is to be expected, adverse criticism of these papers in the light of more modern knowledge is inevitable. To cite only one example, that which represents serum treatment as vaccine treatment in disguise-it being suggested that bacterial products with which the animal has been immunized are present in the serum and are the source of its activity-cannot be taken seriously. A third way of regarding this publication is as a stimulus to more critical thought and to further investigation. We may disagree with most of it, but it would be more constructive and useful if we had something practical to offer in its stead. We can now successfully treat many acute infections, but we are very much as we were in dealing with many chronic ones. We do not know why they recur or persist in an otherwise healthy individual, in spite sometimes of a high degree of humoral immunity, or at least of every effort to produce it. The only adequate answer to the vaccine doctrine will be to expose the undiscovered factor of which it takes no account.

\section{ASSESSING THE FOSTER PARENT}

In Quest of Foster Parents. By Dorothy Hutchinson. (Pp. 145. 11s. 6d.) New York: Columbia University Press; London: Oxford University Press. 1943

Even before the war many children every year had homes found for them with adoptive parents or guardians by voluntary agencies or local authorities. The need for evacuation from the towns turned into home-finders many thousands of persons with neither experience nor knowledge. This book should have been available at that time, but its value will none the less be permanent and considerable. It fills a want which many workers in this country must have felt. Miss Hutchinson, who is assistant professor of social work in the New York School of Social Work, restricts herself to the choice and evaluation of foster parents who apply to social agencies or to social 